\title{
Tax-optimal step-up and imperfect loss offset
}

\begin{abstract}
In the field of mergers and acquisitions, German and international tax law allow for several opportunities to step up a firm's assets, i.e., to revaluate the assets at fair market values. When a step-up is performed the taxpayer recognizes a taxable gain, but also obtains tax benefits in the form of higher future depreciation allowances associated with stepping up the tax base of the assets. This tax-planning problem is well known in taxation literature and can also be applied to firm valuation in the presence of taxation. However, the known models usually assume a perfect loss offset. If this assumption is abandoned, the depreciation allowances may lose value as they become tax effective at a later point in time, or even never if there are not enough cash flows to be offset against. This aspect is especially relevant if future cash flows are assumed to be uncertain. This paper shows that a step-up may be disadvantageous or a firm overvalued if these aspects are not integrated into the basic calculus. Compared to the standard approach, assets should be stepped up only in a few cases and - under specific conditions - at a later point in time. Firm values may be considerably lower under imperfect loss offset.
\end{abstract}

JEL classifiation: $\mathrm{H} 25 ;$ M41

Keywords: business taxation, hidden reserves, step-up

Manuscript received May 3, 2010, accepted by Rainer Niemann (Accounting) November 4, 2011.

\section{Introduction}

The fair market values of assets can exceed their book values substantially. German and international tax law offer several opportunities to disclose these so-called hidden reserves. All these opportunities have in common that book values are stepped up to their fair market values. As a result, hidden reserves are taxed and can be written off in the future due to a higher book value of the assets. Generally a step-up is advantageous if the positive tax rate effect of disclosing hidden reserves at a reduced tax rate outweighs the negative timing effect of depreciating the stepped-up tax base in future years.

There are two different step-up occasions: those in connection with a transaction in which a price for the assets is paid, and those without a transaction. In the latter case, the legislator has to determine a fair market value (step-up value).

The choice between asset deal and share deal one that is available in almost every tax regime - can be seen as an example of the first kind. If shares in a target firm are bought, the tax base of the underlying assets is generally not stepped up. If, on the contrary, the assets of a limited liability corporation are purchased, the target's assets may be stepped up to fair market value. If the transferee pays a consideration in excess of the fair market value, that excess is regarded as goodwill. Under Section 338 of the U.S. Internal Revenue Code (IRC), even if the target's stock is purchased, the transaction can be treated as a hypothetical asset deal for tax purposes. At the firm level, then, there is a choice between book value and fair value in the case of a transaction. Erickson and Wang (2007) showed under which conditions such a step-up is advantageous under US tax law in the context of $\mathrm{S}$ and $\mathrm{C}$ corporations and proved their results empirically. In addition, Erickson and Wang (2000) found that the step-up benefits are positively correlated with acquisition premiums. Let us take German tax law as an example of the second kind. According to the Reorganization Tax Act (Umwandlungssteuergesetz) mergers and conversions of business enterprises can be performed 
at book value or at fair market value or every value in between (§§ 3, 11, 20 para. 2 UmwStG). Accordingly, without any market transaction, i.e. without a price being paid for the hidden reserves, the taxpayer may disclose these at firm level at any amount up to their fair market value. This regulation has been examined from a tax-planning point of view by, e.g., Brähler, Göttsche, and Rauch (2009) and Müller and Semmler (2003a).

With reference to US tax law Erickson (1998) and Schipper and Smith (1991) come to the conclusion that the immediate tax cost of disclosing hidden reserves often exceeds future tax benefits. Schipper and Smith (1991: 327), pointed out that this is potentially because "the firm may not generate sufficient income in the post-buyout period to take full advantage of the increased deductions." This argument will play an important role in this paper. There are several similarities to the so-called tax exhaustion (the point at which an additional euro tax deduction does not reduce tax payments further) theory, which states that firms with a high probability of facing a tax exhaustion status are less likely to finance with debt (MacKie-Mason 1990). The depreciation of the acquisition price/step-up value can also lead to tax exhaustion status in future periods, which would cause a reduction in the value of the depreciation tax shield and, therefore, in the acquisition premium.

DeAngelo and Masulis (1980) showed that as a firm's depreciation allowances increase its demand for interest deductions declines (substitution effect). In the following, the opposite effect is described analytically. Depending on the tax-effective future cash flows, which of course are diminished by future interest deductions, the maximum and optimal step-up value and thus the resulting depreciation deductions decrease with rising interest deductions.

While empirical studies indicated that tax payers do take into account whether certain deductions are tax effective or not, most analytical models in the fields of M\&A assume an immediate loss offset (Müller and Semmler 2003a; Müller and Semmler 2003b; Müller, Langkau, and Schmidt 2011; Scholes, Wolfson, Erickson, Maydew, and Shevlin 2009: 405 et seq.). This gap shall be closed in the following.

In this paper an analytical model is set up and the optimal and maximum step-up values and their optimal timing are derived, with special consider- ation given to imperfect loss offset and uncertainty. These features distinguish this examination from previous tax-planning studies. As indicated above, the country-specific step-up rules differ in detail, but coincide in their basic principles ( $\mathrm{PwC}$ 2006). For this reason, the following model abstracts from a given tax regime and instead focuses on the basic tax effects in order to achieve general results.

I show that restricting depreciation allowances to the cash flows influences the step-up calculus considerably. There is not only an optimum but also a maximum step-up value, which should not be exceeded. Taking an uncertain lifetime of the investment into account, both values may decrease further. Also, in the field of acquisitions the buyer's price diminishes. The standard calculus would lead to wrong decisions.

The aim of the paper is twofold: On the one hand, it of course addresses tax-planners: they need to know whether to choose the step-up alternative or not, or how to calculate the acquisition premium. The standard model only tells them to compare the step-up tax with the tax savings from the depreciation allowances, which are assumed to be certain. This does not allow them to take uncertainty or imperfect loss offset into consideration. Apart from the tax- planning function, my model also permits tax policy conclusions. The question in this case could be: If tax authorities want taxpayers to disclose their hidden reserves, to what extent does the step-up tax rate have to be lowered? The cause-and-effect link of the tax planners' view is transformed into a goal-and-means link of the tax authorities' view.

On the other hand, the main propositions of the paper can be tested empirically. For example, an examination can be made to determine whether there is a "reverse" substitution effect between interest deductions and step-up value, or if asset deal acquisition premiums can be better explained by the suggested approach.

The remainder of the paper is organized as follows. Section 2 presents the calculus of a tax-optimal step-up under certainty. In section 3 uncertainty concerning the lifetime of the investment is introduced and in section 4 the optimal point in time of the step-up is determined. Section 5 concludes with a summary. 


\section{Step-up under certainty}

The following model calculates the net present value of the step-up (NPV). The step-up decision can be regarded as an investment decision. The tax payment on the step-up, which can be calculated by multiplying the disclosed hidden reserves $A$ by the reduced tax rate $s_{r}$, is the outflow of the investment in $t=0$, while the tax savings (tax rate $s$ ) that result from the depreciation $\left(\operatorname{dep}(t), \int_{0}^{U L} \operatorname{dep}(t) d t=1\right)$ of the disclosed hidden reserves over their useful lives $(U L)$ are the future cash flows. Initially, all variables are considered to be deterministic so there is no uncertainty concerning future cash receipts.

\subsection{Perfect loss offset}

Assuming a perfect loss offset means that depreciation allowances are always tax-effective, even if there are not enough profits against which they can be offset. The net present value of the stepup investment in continuous time, which is to be maximized, can then be described as follows $\left(i_{s}\right.$ : after-tax interest rate; for simplicity it is assumed that all book values before the step-up are zero):

$$
\begin{aligned}
& \max _{A} N P V(A)= \\
& -\mathrm{s}_{r} \cdot A+s \int_{0}^{U L} A \cdot \operatorname{dep}(t) \cdot e^{-i_{s} \cdot t} d t
\end{aligned}
$$

Of course, the NPV can only be positive and therefore a planning problem only exists if hidden reserves are taxed at a reduced tax rate $\left(s_{r}\right)$. This is a realistic assumption that is illustrated in brief by the following examples:

- National tax regimes often allow for a reduced tax rate if hidden reserves, which have been built up over years, are disclosed, especially to avoid the negative effects of a progressive tax schedule. For instance, German tax law applies a reduced tax rate if business enterprises are sold or if they are converted into a corporation at fair market values.

- Under certain circumstances existing loss carry-forwards may vanish (e.g., if corporations are merged or sold). These loss carry-forwards can be transformed into depreciable assets by disclosing hidden reserves; despite existing loss carry-forwards, in many countries a part of the step-up value may be taxed due to minimum tax regulations, which leads also to a reduced tax rate.

- There are many situations in which today's tax rate on hidden reserves differs from the tax rate in future years because of tax reforms, progressive tax rates etc.

If disclosing hidden reserves also has effects on financial as well as tax accounting, it is possible that non-tax aspects will influence the step-up decision, especially as far as dividend payments are concerned. In the case of a merger or conversion, according to German tax law (or any other tax law with a two-book system) there is no link between financial income and taxable income, and the problem is a mere tax minimization problem. In the case of an asset or share deal transaction non-tax aspects may play a role. For complexity reasons I leave them aside and treat the problem as a mere tax minimization problem.

The step-up calculus can then be explained as follows.

If the tax rate effect exceeds the time effect of taxation, the assets should be stepped up.

(2) $\mathrm{s}_{r} \leq s \int_{0}^{U L} \operatorname{dep}(t) \cdot e^{-i_{s} \cdot t} d t$

If the taxpayer is able to influence the step-up value $A$, the latter should be as high as possible in order to maximize the NPV.

The same calculus is valid for firm acquisitions. In the case of an asset deal the first part of equation (1) describes the situation of the seller, who has to pay taxes on the disclosed hidden reserves $\left(s_{r} \cdot A\right)$. The second part quantifies the depreciation tax savings of the acquirer. The only difference is that in this scenario $A$ represents the acquisition price $P$, which cannot be set by the tax payer but rather results from a maximum/minimum price calculus, which is explained in the following.

Without selling the firm the investor realizes the after-tax discounted cash flow value $P V_{C F}$; if he sells the firm, he has to pay (reduced) taxes on the proceeds of the sale $(P)$. In order to be indifferent to the situation without selling the firm, the seller has to demand a minimum price, which after taxation still equals his pre-acquisition discounted cash flow value, i.e.

(3) $\mathrm{P} \cdot\left(1-s_{r}\right) \geq P V_{C F} \Rightarrow P \geq \frac{P V_{C F}}{1-s_{r}}$ 
Corresponding to the taxation of the seller's proceeds the buyer is allowed to depreciate the price (acquisition costs) $P$; these depreciation allowances lower future tax payments. Therefore, the buyer is willing to pay a price up to these tax savings, over and above the present value of the cash flows:

\section{(4) $\mathrm{P} \leq$}

$$
\begin{aligned}
& \mathrm{PV}_{C F}+s \int_{0}^{\mathrm{UL}} P \cdot \operatorname{dep}(t) \cdot e^{-t \cdot i_{s}} d t \Rightarrow \\
& \mathrm{P} \leq \frac{P V_{C F}}{1-s \cdot \int_{0}^{\mathrm{UL}} \operatorname{dep}(t) \cdot e^{-t \cdot i_{s}} d t}
\end{aligned}
$$

Assuming identical cash receipts for seller and buyer, an acquisition with disclosed hidden reserves will only take place if

(5) $\mathrm{s}_{r} \leq s \cdot \int_{0}^{\mathrm{UL}} \operatorname{dep}(t) \cdot e^{-t \cdot i_{s}} d t$

which is identical to equation (2). These approaches in discrete time are well known in business taxation literature (Scholes, Wolfson, Erickson, Maydew, and Shevlin 2009:405 et seq.; Schreiber 2008: 742 et seq.).

\subsection{Imperfect loss offset}

Under the regime of an imperfect loss offset, depreciation allowances are not recognized as expenses and therefore are not tax-effective as far as they exceed the investment's cash flows; instead a tax loss carry-forward is induced which reduces taxes in future periods, but only if there are sufficient taxable cash flows. The after-tax interest rate is not influenced by an existing loss carry-forward, as I assume that the cash flows are not reinvested at company level and thus interest income cannot be offset against the loss carry-forward. I therefore assume $i_{s}$ to be independent of the actual profit or loss situation. There are no tax-effective cash flows from other investment projects against which the remaining depreciation allowances can be offset. This assumption seems especially relevant in the present scenario (merger and acquisition) because it is not a single investment project that is valued but rather a bundle of projects, and the taxeffective cash flow is already the net cash flow of all the firm's investment projects.

\subsubsection{Simplified Approach}

In the following the depreciation allowances of formula (1) are replaced by the underlying cash flows by which the former are limited, i.e. I assume that the cash flows restrict the depreciation allowances at every point in time $t$, which allows us to focus on the cash flows. Later on I depart from this simplifying assumption and analyze the consequences. I will restrict the analysis to geometrically increasing or decreasing cash flows.

Given the starting cash flow $C F$ and the growth rate $\omega$ it has to be determined at which point in time $x$ the step-up amount $A$ is amortized by the cash flows:

$$
\int_{0}^{x} \mathrm{CF} \cdot e^{t \cdot \omega} d t=A \Rightarrow x=\frac{\log \left[\frac{A \cdot \omega}{C F}+1\right]}{\omega}
$$

Now the NPV of the step-up investment can be calculated by substituting the depreciation function for the cash flow function:

$$
\text { (7) } \begin{aligned}
& N P V(\mathrm{~A})= \\
& -\mathrm{A} \cdot \mathrm{s}_{r}+s \int_{0}^{\frac{\log \left[\frac{\mathrm{A} \cdot \omega}{\mathrm{CF}}+1\right]}{\omega}} \mathrm{CF} e^{t \cdot\left(\omega-i_{s}\right)} d t \\
& =-\mathrm{A} \cdot s_{r}+s \frac{\mathrm{CF} \cdot\left(\left(1+\frac{\mathrm{A} \omega}{\mathrm{CF}}\right)^{1-\frac{i_{s}}{\omega}}-1\right)}{\omega-i_{s}}
\end{aligned}
$$

First it is assumed that the taxpayer can determine the step-up value of the asset. This could be the case if there was no underlying market transaction in connection with the step-up. The step-up value is therefore determined by means of financial theory or comparable market transactions, which always offer a range of possible values depending on the parameters that are used. In the case of a conversion or a merger German tax law explicitly allows for any value between book value and fair market value. Finally, even in the case of an underlying market transaction it may be possible to influence the amount of disclosed hidden reserves; for example, an acquisition could be managed as a part asset, part share deal.

In order to determine the optimal step-up value, equation (7) has to be differentiated with respect to $A$, which leads to the following first-order condition

(8) $\mathrm{s}\left(1+\frac{A^{*} \omega}{\mathrm{CF}}\right)^{-\frac{i_{s}}{\omega}}-s_{r}=0$

and because of concavity, to the optimal step-up value $A^{*}$

(9) $\mathrm{A}^{*}=\frac{\mathrm{CF} \cdot\left(-1+\left(\frac{s_{r}}{s}\right)^{-\frac{\omega}{i_{s}}}\right)}{\omega}$ 
For the special case of time-discrete, constant cash flows $(\omega=0)$, Brähler, Göttsche, and Rauch (2009) found a similar result. Concentrating on the tax rate relation $\frac{s_{r}}{s}$, comparative statics shows that $A^{*}$ increases if the relation $\frac{s_{r}}{s}$ decreases, as the costs of disclosing hidden reserves at tax rate $s_{r}$ decline compared to the earnings of the future depreciation allowances, which become tax-effective at tax rate $s$. It can also be seen that if there is no reduced tax rate $\left(s_{r}=s\right)$, hidden reserves should not be disclosed at all as $A^{*}$ becomes zero. On the other hand, as long as there is no taxation on the step-up $\left(s_{r}=0\right)$, there is no maximum value of disclosure as $A^{*}$ goes to infinity.

In most cases the step-up value cannot be determined by the taxpayer, but is prescribed by the legislator or results from an underlying transaction. In this case the question arises as to whether the $N P V$ of a given step-up value is greater or less than zero, i.e., the root of function (7) is sought. Although there is no general analytical solution, closed-form solutions for special cases are possible. In the following, three special cases are analyzed. Assuming an infinite cash flow series, $\omega$ must not exceed $i_{s}$ to achieve reasonable results using the valuation formula $\frac{C F(1-s)}{i_{s}-\omega}$. Formula (7) is not defined for this extreme value $\left(i_{s}=\omega\right)$; however, l'Hôpital's rule can be applied and thus formula (7) simplifies to

$$
\begin{aligned}
& \lim _{\omega \rightarrow i_{s}} N P V(A)= \\
& s \frac{\mathrm{CF} \cdot \log \left(1+\frac{A \cdot i_{s}}{\mathrm{CF}}\right)}{i_{s}}-A \cdot s_{r}
\end{aligned}
$$

As a second special case I assume $\omega=0$, i.e. constant cash receipts over time; here, too, formula (7) is not defined and l'Hôpital's rule must be applied:

$$
\begin{gathered}
\lim _{\omega \rightarrow 0} N P V(A)= \\
s \frac{\mathrm{CF} \cdot\left(1-e^{-\frac{A \cdot i_{s}}{\mathrm{CF}}}\right)}{i_{s}}-A \cdot s_{r}
\end{gathered}
$$

Finally, negative growth rates are analyzed; in the case of $\omega=-i_{s}$ formula (7) turns into the quadratic equation

$$
N P V(\mathrm{~A})=-\mathrm{A} \cdot s\left(\frac{A \cdot i_{s}}{2 \cdot \mathrm{CF}}-1\right)-A \cdot s_{r}
$$

By setting equations (10), (11) and (12) equal to zero and solving for $A$ (setting $v=\frac{s_{r}}{s}$ ) the maximum step-up values are determined (neglecting the possible solution $A=0$ ), which are shown in Table 1. For details concerning the Lambert W function see Appendix A1 and for the derivation of (16) see Appendix A2.

By analogy the maximum prices of the buyer can be determined by replacing the second part of formula (4) by the first part of equation (11) and (12) setting $P V_{C F}=\frac{C F(1-s)}{i_{s}}$ (discounted after-tax cash flows); these are also shown in Table 1 (there are no reasonable valuation results for $\omega=i_{s}$ ).

From these maximum prices $P$ the necessary reduced tax rate of the seller can be derived by inserting formulae (15) and (17) into formula (3) and solving for $s_{r}$ :

$$
\begin{aligned}
& \mathrm{S}_{r, \omega=0} \leq 1+\frac{-1+s}{1+\mathrm{W}\left[-\frac{s}{e}\right]} \\
& \mathrm{S}_{r, \omega=-i_{s}} \leq \frac{1}{2}(1-\sqrt{1-s}+s)
\end{aligned}
$$

It can be shown that by inserting these reduced tax rates into the corresponding formulae (14) and (16) one receives the maximum price of the buyer according to formulae (15) and (17). That means that the maximum step-up value and the firm price coincide provided there is price congruence, i.e. the minimum price of the seller equals the maximum price of the buyer. In the following I will restrict the analysis to the maximum step-up value and thus combine the buyer's and the seller's view. Of course the analysis could also be performed concentrating on the maximum price of the buyer.

Figure 1 illustrates the step-up calculus $(N P V(A))$ and the analogous application to firm valuations $(P(A))$.

The function $N P V(A)$ describes the net advantage, which is generated by a step-up without a market transaction according to formula (7). It starts at zero, has a maximum value and returns to zero. The slope of the function changes as the present value of tax-effective cash flows, against which the depreciation allowances can be offset, decreases. The remaining functions describe the acquisition case. Here, because of the underlying market transaction, the step-up value $(A)$ is linked to the acquisition price $(P)$, which is expressed by the function $P(A)=A$. All possible combinations of $A$ and $P$ lie on this function. Starting from the firm value without any depreciation deductions $\left(P V_{C F}\right)$ the buyer is willing to pay a higher price with an increasing depreciable step-up value $(A)$ and the seller demands a higher price as he has to pay taxes 
Table 1: Maximum step-up value and price

$A^{\operatorname{Max}}$ $P^{M a x}$

(13)

$\mathrm{A}_{\omega=i_{s}}^{\operatorname{Max}}=\frac{\mathrm{CF} \cdot\left(-1-\frac{1}{v} \mathrm{~W}\left(-e^{-v} \cdot v\right)\right)}{i_{s}}$

(14) $\mathrm{A}_{\omega=0}^{\operatorname{Max}}=\frac{\mathrm{CF} \cdot\left(\mathrm{W}\left(-e^{-\frac{1}{v} \cdot \frac{1}{v}}\right)+\frac{1}{v}\right)}{i_{s}}$

(15) $\quad \mathrm{P}_{\omega=0}^{\operatorname{Max}} \leq \frac{\mathrm{CF}\left(1+\mathrm{W}\left(-\frac{s}{e}\right)\right)}{i_{s}}$

(16)

$$
\mathrm{A}_{\omega=-i_{s}}^{\operatorname{Max}}= \begin{cases}\frac{2 \cdot \mathrm{CF}(1-v)}{i_{s}} & \text { for } v \geq \frac{1}{2} \\ \frac{\mathrm{CF}}{2 i_{s} \cdot v} & \text { for } v<\frac{1}{2}\end{cases}
$$

$$
\mathrm{P}_{\omega=-i_{s}}^{\operatorname{Max}} \leq \frac{\mathrm{CF}(-1+\sqrt{1-s}+s)}{s \cdot i_{s}}
$$

Figure 1: $N P V, P$ depending on $A$

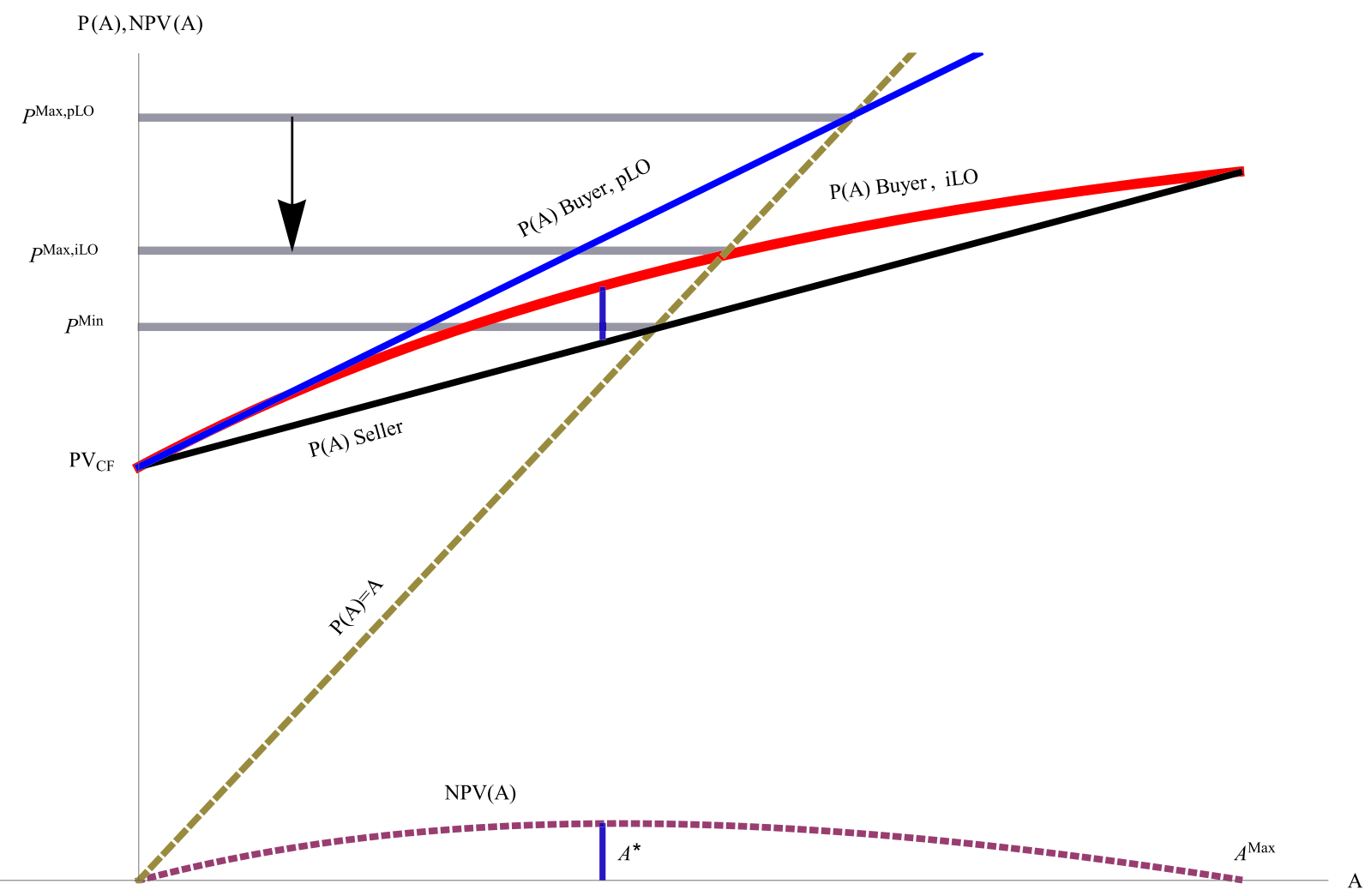

on the disclosed hidden reserves. In the standard approach these functions show a linear course. Due to the reasons mentioned above, in the case of an imperfect loss offset the buyer's function is concave.

At the intersection of these functions with the function $P(A)=A$ is the maximum price the buyer is willing to pay depending on the scenario. Of course, the maximum price in the case of a perfect loss offset $\left(P^{M a x, p L O}\right)$ lies above that in the case of an imperfect loss offset $\left(P^{M a x, i L O}\right)$. The difference diminishes the negotiable acquisition premium. The minimum price of the seller is of course not influenced by the loss offset scenario.

Figure 1 shows that the calculus in the acquisition case and in the step-up case are essentially the same 
(graphically they are rotated and shifted, though); the only difference is that in the acquisition case the $N P V$ of the step-up investment is distributed between buyer and seller. In both cases a step-up is advantageous only for $A<A^{\operatorname{Max}}$; otherwise a transaction should rather be carried out as a share deal and a conversion performed at book values. As mentioned above, I will concentrate on the more general step-up calculus.

\subsubsection{Detailed Approach}

In this section I abandon the simplifying assumption that depreciation allowances exceed or at least equal the cash flows at every point in time and analyze under which conditions the results still hold. In this case the given depreciation allowances have to be taken into account. It is necessary to distinguish between increasing and decreasing cash flows.

Increasing cash flows If the depreciation allowances exceed the cash flows, they are only taxeffective in the amount of the cash receipts. The remainder leads to a loss carry-forward, which becomes tax-effective as soon as cash flows exceed depreciation allowances. Figure 2 illustrates the calculus for both a low step-up value $A^{\prime}$ and a high step-up value $A^{\prime \prime}$

The straight line depreciation allowances can be calculated by dividing the step-up value by the useful life of the asset $\left(\operatorname{dep}(t):=\frac{A}{U L}\right)$. It can be seen that in the case of a low step-up value $\left(A^{\prime}\right)$ the cash receipts are not restricting and the depreciation allowances are fully tax effective; however, a high

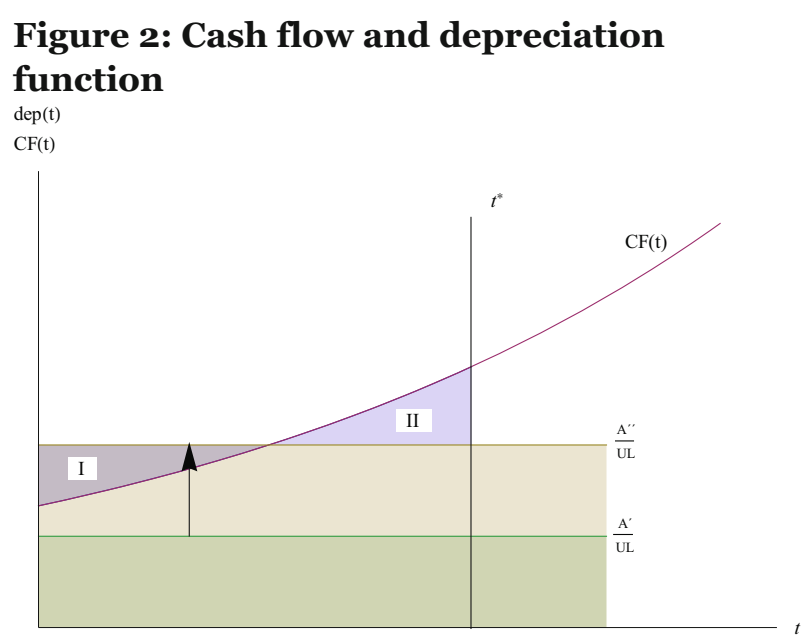

step-up value $\left(A^{\prime \prime}\right)$ causes a loss carry-forward in the amount of area I, which can only be offset against future cash receipts in addition to the existing depreciation allowances (area II). The arrow indicates that the higher the step-up value $A$, the more restrictive the cash flows until they are solely restrictive.

Equation (20) calculates at what point in time $t^{*}$ the accrued loss carry-forward (area I) is recovered completely by future earnings (area II):

$$
\begin{aligned}
& \int_{0}^{t^{*}}\left(\mathrm{CF} e^{\omega t}-\frac{A}{\mathrm{UL}}\right) d t= \\
& \frac{\mathrm{CF} \cdot\left(-1+e^{*} \omega\right)}{\omega}-\frac{A \cdot t^{*}}{\mathrm{UL}}=0
\end{aligned}
$$

Solving equation (20) for $t^{*}$ using the Lambert $\mathrm{W}$ function yields:

$$
\mathrm{t}^{*}=\frac{-\mathrm{CF} \cdot \mathrm{UL}-A \cdot \mathrm{W}\left(-\frac{\mathrm{CF} \cdot e^{-\frac{\mathrm{CF} \cdot \mathrm{UL}}{A}}}{A}\right)}{A \cdot \omega}
$$

The function $W(z)$ is multivalued for $\frac{-1}{e} \leq z<0$, i.e., there are two possible real values of $W(z)$. One of them always leads to the trivial solution $t^{*}=0$. Therefore, the solution of the second branch, which is often referred to as $W_{-1}(z)$ (Chapeau-Blondeau and Monir 2002), is relevant.

Knowing $t^{*}$ the NPV of the step-up investment depending on $A$ can be calculated as follows. As long as the cash receipts do not limit the depreciation allowances, the basic calculus assuming full loss offset is valid. Here, depreciation allowances have to be lower than $C F$. Therefore, $\frac{A}{U L} \leq C F \Rightarrow A \leq C F \cdot U L$ must hold. For very high values of $A$ only the cash flows are restricting and the calculus of the simplified approach according to (7) can be applied. This is the case if $t^{*}$ lies above $U L$, which determines the second threshold. Solving (21) for $A$ setting $t^{*} \geq U L$ one obtains $A \geq \frac{\mathrm{CF}\left(-1+e^{\mathrm{UL} \omega}\right)}{\omega}$. For values of $A$ between these thresholds the cash flows limit the depreciation allowances until point in time $t^{*}$; from that point in time onwards the present value of the depreciation allowances has to be calculated. 
(22) $\quad \mathrm{NPV}(\mathrm{A})=$

$$
\left\{\begin{array}{l}
s \int_{0}^{\mathrm{UL}} \frac{A}{\mathrm{UL}} \cdot e^{-t \cdot i_{s}} d t-A \cdot s_{r} \\
\text { for } A<C F \cdot U L \\
s\left(\int_{0}^{t^{*}(A)} \mathrm{CF} e^{t\left(\omega-i_{s}\right)} d t+\int_{t^{*}}^{\mathrm{UL}(A)} \frac{A}{\mathrm{UL}} e^{-t \cdot i_{s}} d t\right)-A s_{r} \\
\operatorname{for} C F \cdot U L \leq A<\frac{\mathrm{CF}\left(-e^{\mathrm{UL} \omega}\right)}{\omega} \\
\frac{\operatorname{cor}\left(-1+\left(1+\frac{A \omega}{\mathrm{CF}}\right)^{1-\frac{i_{s}}{\omega}}\right)}{\omega-i_{s}}-A \cdot s_{r} \\
\text { for } A \geq \frac{\mathrm{CF}\left(-1+e^{\mathrm{UL} \cdot \omega}\right)}{\omega}
\end{array}\right.
$$

Figure 3 illustrates formula (22) for CF $:=.04, s:=$ $.5, s_{r}:=0.25, i_{s}:=.06, \omega:=.05$.

It shows that the NPV that focuses only on the cash flows limits the NPV that is calculated using straight-line depreciation with an assumed useful life of 15 and 20 years, respectively (NPV_15/20). The shorter the useful life, i.e., the higher the depreciation allowances, the sooner the functions converge with the NPV function because the depreciation allowances in the first periods increase such that the loss carry-forward is not recovered until the end of the depreciation period. The taxeffective depreciation allowances hence decrease or increase to the level of the cash flows over the whole depreciation period. In addition, the maxima of the functions differ. The maxima of (22) cannot be analytically determined according to (9). Of course there is a numerical solution for the individual case. However, as the functions coincide for moderate depreciation periods before the zero point is reached, all conclusions concerning the maximum step-up value are still valid.

Figure 3: $N P V(A)$ for $C F:=.04, s:=.5$, $s_{r}:=0.25, i_{s}:=.06, \omega:=.05$

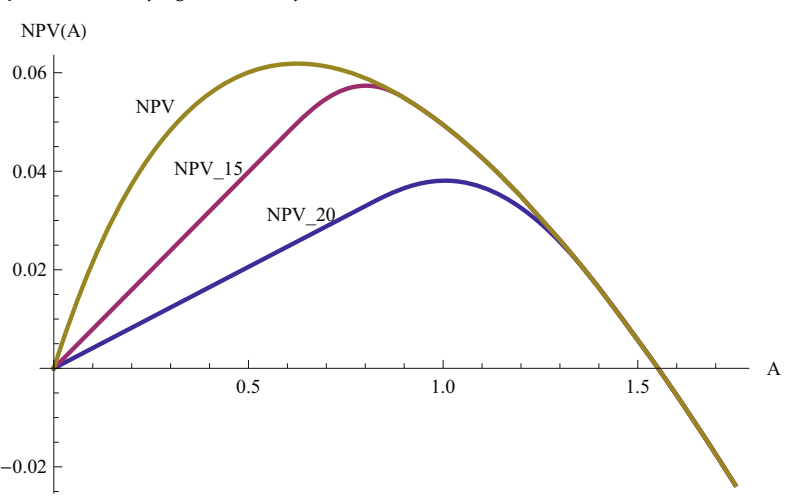

Decreasing cash flows Figure 4 illustrates how the calculus changes if decreasing cash flows are taken into account. Again, for a low step-up value $\left(A^{\prime}\right)$ the basic calculus is valid as the cash flows never fall below the depreciation allowances. For medium step-up values $\left(A^{\prime \prime}\right)$, however, in contrast to Figure 2, tax-effective earnings in early periods cannot be used completely; a loss carryforward accrues as soon as the cash flow function falls below the depreciation function $\left(t>t^{\circ}\right)$ and is used after the depreciation period has ended.

The intersection of the cash flow function and depreciation function can be determined by solving the equation $C F(t)=\operatorname{dep}(t) \Rightarrow \mathrm{CF} e^{\omega t}-\frac{A}{\mathrm{UL}}=0$, which results in $t^{\circ}=\frac{\log \left[\frac{A}{C F . U L}\right]}{\omega}$. From this point onwards a loss carry-forward accrues. In contrast to Figure 2 this loss carry-forward cannot be used until the depreciation period has ended. By equating area I (loss carry-forward) with area II (use of loss carry-forward) the point in time $t^{* *}$ until which the cash receipts are tax-exempt can be calculated:

$$
\begin{aligned}
& \int_{\frac{\mathrm{Log}\left[\frac{A}{\mathrm{C} \cdot \mathrm{UL}}\right]}{\omega}}^{\mathrm{UL}}\left(\frac{A}{\mathrm{UL}}-\mathrm{CF} e^{\omega \cdot t}\right) d t= \\
& \int_{\mathrm{UL}}^{t^{* * *}} \mathrm{CF} \cdot e^{\omega \cdot t} d t \\
& \Rightarrow t^{* *}=\frac{\log \left[\frac{A\left(1+\mathrm{UL} \cdot \omega-\mathrm{Log}\left[\frac{A}{\mathrm{CF} \cdot \mathrm{UL}}\right]\right)}{\mathrm{CF} \cdot \mathrm{UL}}\right]}{\omega}
\end{aligned}
$$

Thus the net present value of the step-up investment reads:

\section{Figure 4: Cash flow and depreciation function}

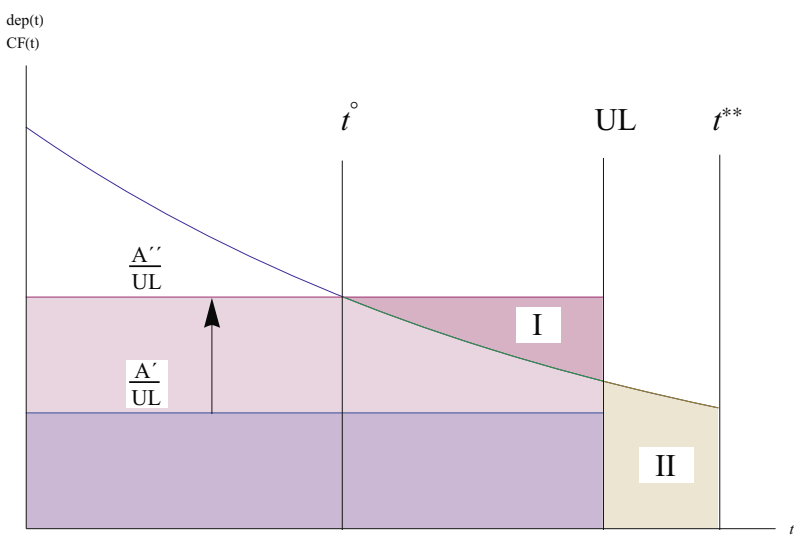


(24) $\quad N P V(\mathrm{~A})=$

$$
\left\{\begin{array}{l}
s \int_{0}^{\mathrm{UL}} \frac{A}{\mathrm{UL}} \cdot e^{-t \cdot i_{s}} d t-A \cdot s_{r} \\
\text { for } A<\mathrm{CF} \cdot e^{\mathrm{UL} \cdot \omega} \cdot \mathrm{UL} \\
s \cdot\left(\int_{0}^{t^{0}} \frac{A}{\mathrm{UL}} e^{-t \cdot i_{s}} d t+\int_{t^{\circ}}^{t^{* *}} \mathrm{CF} e^{t^{\circ}\left(\omega-i_{s}\right)} d t\right)-A s_{r} \\
\text { for } \mathrm{CF} \cdot e^{\mathrm{UL} \cdot \omega} \cdot \mathrm{UL} \leq A<\mathrm{CF} \cdot \mathrm{UL} \\
\frac{\mathrm{CF} \cdot s\left(-1+\left(1+\frac{A \omega}{\mathrm{CF}}\right)^{1-\frac{i_{s}}{\omega}}\right)}{\omega-i_{s}}-A \cdot s_{r} \\
\text { for } A \geq \mathrm{CF} \cdot \mathrm{UL}
\end{array}\right.
$$

The thresholds can be determined in analogy to the previous section: If the depreciation allowances lie below the cash flow function until the useful life of the asset is reached, there is no restrictive effect and the basic calculus can be applied. Therefore $\frac{A}{U L}<$ $C F \cdot e^{U L \cdot \omega} \Rightarrow A<C F \cdot e^{U L \cdot \omega} \cdot U L$ must hold. Only the cash flows are restricting if $\frac{A}{U L}>C F$. Therefore, the second threshold reads $A>C F \cdot U L$. The thresholds differ from the last paragraph, though the course of the NPV functions and therefore the interpretation is very similar to Figure 3.

\subsubsection{Simplified vs. detailed approach}

It can be seen that the NPV functions of the detailed approach for both increasing and decreasing cash receipts coincide for high step-up values with those of the simplified approach; at what level of $A$ both functions coincide depends especially on the given depreciation period. The shorter the depreciation period, the higher the slope of the first part of the functions in the detailed approach and the earlier the coincidence with the simplified function. If both functions meet before point zero is reached, only the simplified approach is necessary to determine the maximum step-up value $A$.

Finally I analyze under which conditions it is possible to exclusively use the simplified approach. From (22) it can be seen that-in the case of increasing cash receipts-the functions coincide for $A \geq \frac{\mathrm{CF}\left(-1+e^{\mathrm{UL} \cdot \omega}\right)}{\omega}$. For $\omega=i_{s}$ the maximum step-up value is determined by (13). Equating both and solving for the useful life yields:

$$
\mathrm{UL}^{*}=\frac{\log \left(-\mathrm{W}\left(-e^{-v} \cdot v\right) \cdot \frac{1}{v}\right)}{i_{s}}
$$

$U L^{*}$ denotes the useful life which may not be exceeded in order to obtain the same maximum step-up value in the detailed approach as in the simplified approach. The values in the scenario $\omega=0$ can be determined by analogy. In this case $\frac{\mathrm{CF}\left(-1+e^{\mathrm{UL} \omega}\right)}{\omega}$ changes to $U L \cdot C F$ :

$$
\mathrm{UL}^{*}=\frac{s+\mathrm{W}\left(-e^{-\frac{1}{v} \cdot \frac{1}{v}}\right) s_{r}}{i_{s} \cdot s_{r}}
$$

This turns out to be the same useful life that is necessary to satisfy condition (2) for a straight line depreciation; as both cash receipts and depreciation allowances have a slope of zero the first and second threshold of formula (22), respectively (24) coincide.

Finally, for the negative growth rate $\omega=-i_{s}$ formula (16) has to equal the last threshold of formula (24); this leads to

$$
\mathrm{UL}^{*}= \begin{cases}\frac{2(1-v)}{i_{s}} & \text { for } v \geq \frac{1}{2} \\ \frac{1}{2 i_{s} \cdot v} & \text { for } v<\frac{1}{2}\end{cases}
$$

Figure 5 shows the necessary useful lives depending on the reduced tax rate for $i_{S}:=.04$ and $s:=.5$. The $\omega=0$-function depicts-as mentioned above-the maximum useful life that is necessary for the step-up to be advantageous in the first place. In Figure 3 this useful life would lead to a slope of zero. In all other scenarios the depreciation allowances have to be higher, i.e. useful life has to be shorter. But as Figure 5 shows, even in the case of decreasing cash flows the resulting maximum useful lives are quite realistic.

Conclusion In the standard approach with the assumption of a perfect loss offset it is only necessary that equation (1) is satisfied; I show that

Figure 5: $U L$ depending on the the reduced tax rate $s_{r}$ for $i_{s}:=.04$ and $s:=.5$

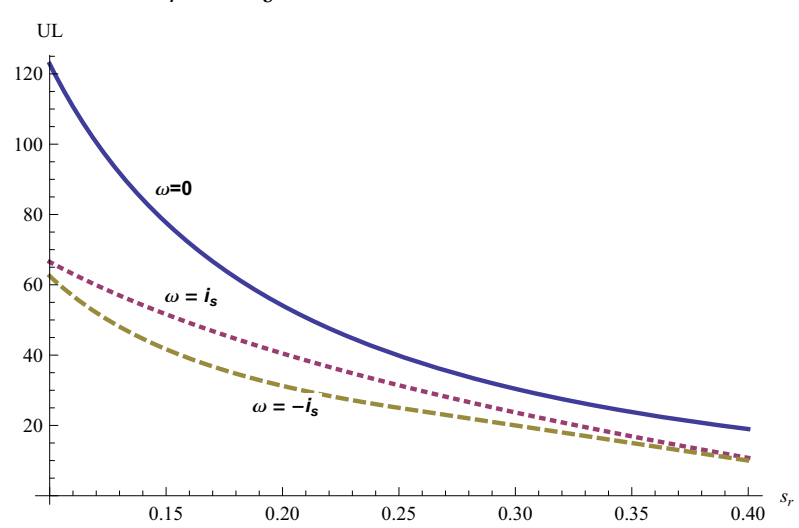


in the case of an imperfect loss offset as an additional condition, the step-up value may not exceed a certain maximum value which depends on the underlying cash flows.

Further, I prove that the acquisition premium in the case of an asset deal may be considerably smaller when assuming an imperfect loss offset. I presented a simplified and a detailed approach to calculate the maximum step-up value and show that for reasonable useful lives, the simplified approach is sufficient for determining the maximum values.

\section{Step-up under uncertainty concerning the lifetime of the investment}

In the previous section I assumed that the underlying investment project lives forever. In the following I introduce uncertainty concerning the lifetime of the investment project (T). At any time $T$, if the project has lasted that long, there is the probability $\lambda d T$ that it will die during the next short interval of time $d T$. So the probability density function of $T$ is

$$
\mathrm{f}(\mathrm{T})=\lambda e^{-\lambda T}
$$

This approach, which is also applied by, e.g., Gryglewicz, Huisman, and Kort (2008), McDonald and Siegel (1986), Dixit and Pindyck (1994: 200 et seq.), is not an economic lifetime approach that would require comparing the alternatives "selling the project at market value" and "continuing the project" at every point in time. Instead-as the market value is zero if the cash flows stop-the technical lifetime of an investment is determined. Because of the memoryless property of the exponential distribution, this approach is less suited to modeling the failure risk of stand-alone technical investments, which normally would increase during the lifetime. However, it is especially suited to modeling the bankruptcy probabilities of enterprises, which may be assumed as constant over time.

Concerning the valuation of expected present values of depreciation deductions, this method has so far only been used in the context of effective tax rates (Diller 2008).

The consequences are twofold. First, if the cash flows stop, the current market value of the project becomes zero and within the scope of an asset impairment the residual book value has to be written off, so the depreciation period is shortened. Second, in the case of an imperfect loss offset, a shortlived project does not generate enough cash flows to be offset against the depreciation allowances. In this case a part of the step-up value does not become tax-effective.

\subsection{Perfect loss offset}

As in section 2, I first examine the case of a perfect loss offset. In the following I again assume straight-line depreciation. If the project dies, the residual book value $\left(A \cdot\left(1-\frac{T}{\mathrm{UL}}\right)\right)$ has to be written off immediately, which is tax-effective under the regime of a perfect loss offset. Before the expected present value of the depreciation-induced tax savings can be calculated, the present value $(P V(T))$ of the latter, depending on the lifetime of the investment $T$, has to be determined.

$$
\text { (29) } \begin{aligned}
& \mathrm{PV}(\mathrm{T})=\mathrm{A} \cdot s \int_{0}^{\mathrm{Min}(\mathrm{UL}, T)} \frac{1}{\mathrm{UL}} e^{-i_{s} t} d t \\
+ & \mathrm{A} \cdot s \cdot \operatorname{Max}\left(1-\frac{T}{\mathrm{UL}}, 0\right) e^{-i_{s} T} \\
= & \mathrm{A} \mathrm{s}\left(e^{-T \cdot i_{s}} \operatorname{Max}\left(0,1-\frac{T}{\mathrm{UL}}\right)\right. \\
+ & \frac{1-e^{-\operatorname{Min}(\mathrm{UL}, T) i_{s}}}{\mathrm{UL} \cdot i_{s}}
\end{aligned}
$$

Assuming a risk-neutral investor, we can now calculate the expected present value of the tax savings by inserting (29) into the density function. The max function is eliminated by splitting up the integral:

$$
\begin{gathered}
\mathrm{E}(\mathrm{PV})=\mathrm{A} \cdot s \int_{0}^{\mathrm{UL}} \lambda \cdot e^{-T \cdot \lambda} \\
\left(e^{-T i_{s}} \cdot\left(1-\frac{T}{\mathrm{UL}}\right)+\frac{1-e^{-T \cdot i_{s}}}{\mathrm{UL} \cdot i_{s}}\right) d T+ \\
\mathrm{A} \cdot s \int_{\mathrm{UL}}^{\infty} \lambda \cdot e^{-T \cdot \lambda} \cdot\left(\frac{1-e^{-\mathrm{UL} \cdot i_{s}}}{\mathrm{UL} \cdot i_{s}}\right) d T= \\
\mathrm{A} \cdot s \frac{\mathrm{UL} \lambda^{2}+\left(1-e^{-\mathrm{UL}\left(\lambda+i_{s}\right)}+\mathrm{UL} \lambda\right) i_{s}}{\mathrm{UL}\left(\lambda+i_{s}\right)^{2}}
\end{gathered}
$$

Comparative statics show that the expected present value function increases linearly in $A$, is concave with respect to $\lambda$ (which will be shown in figure 7) and decreases with an increasing after-tax interest rate.

\subsection{Imperfect loss offset}

As mentioned above, if the cash flows stop, all the remaining book values have to be written off immediately. In the case of an imperfect loss offset 
this depreciation is not tax-effective as far as it would lead to a loss carry-forward, which cannot be used as there are no future cash flows to be offset against. Neither can these loss carry-forwards be transferred and used by another investor, especially in the case of a limited liability corporation, as their loss carry-forward expires in most tax regimes if it is sold or merged. However, in the case of a bankruptcy even a personally liable entrepreneur may not be able to use major loss carry-forwards for lack of future income. Neither can these loss carry-forwards be transferred to the next generation. Therefore, I assume that if cash flows stop, an existing loss carry-forward is valued at zero.

For these reasons the impairment depreciation is only tax-effective if there are enough cash flows to be offset against. Therefore, it is necessary to verify if the investment is (partly) irreversible or not. If the cash flows stop, the value of the project is zero but it may still be possible to sell the plant or machinery. The cost of a (fully) irreversible investment cannot be recovered once it is installed; therefore, there is no resale value against which to offset the depreciation of the residual book value. However, if the investment is only partly irreversible there is a resale value, which may be additionally lowered by bankruptcy costs. To simplify I assume this resale value (net bankruptcy costs) $K$ to be constant over time; in this case, the depreciation of the residual book value $B(T)$ can be offset against these resale earnings. In the simplified approach according to section 2.2.1-which will be assumed in the following-it is not the depreciation allowances that become tax effective but the cash receipts, assuming there is a loss carry-forward in every point in time. Therefore, $B(T)$ not only expresses the residual book value but the part of the step-up value which has not yet become tax effective, i.e. the residual book value and the existing loss carry-forward with $B(T)=A-\int_{0}^{T} \mathrm{CF} e^{t \omega} d t$ until the step-up value has become completely tax effective. To simplify, I will refer to $B(T)$ as residual book value in the following. As long as $K<B$, there are not enough resale earnings in the last period to be offset against the existing residual book value; therefore only $K$ becomes tax effective. If $B<K$, no more than the residual book value can become tax effective. Figure 6 illustrates the calculus.
Again, first the present value $(P V)$ of the tax savings depending on the lifetime of the investment has to be determined concentrating on the cash receipts. Formula (31) has to consider that if the investment project lives from $T=0$ until $T=\frac{\log \left[\frac{A \cdot \omega}{C F}+1\right]}{\omega}$ (s. formula (6)) the step-up value is not yet amortized, i.e., the longer the life of the project, the higher the present value of the tax-effective efforts.

$$
\begin{aligned}
& \text { (31) } \mathrm{PV}(\mathrm{T})= \\
& \mathrm{s} \int_{0}^{T} \mathrm{CF} e^{t\left(\omega-i_{s}\right)} d t+\operatorname{Min}(K, B(T)) \cdot e^{-T \cdot i_{s}} \\
& =s \frac{\mathrm{CF}\left(e^{T\left(\omega-i_{s}\right)}-1\right)}{\omega-i_{s}}+\operatorname{Min}(K, B(T)) \cdot e^{-T \cdot i_{s}}
\end{aligned}
$$

If the investment project lives longer $\left(T>\frac{\log \left[\frac{A \omega \omega}{C F}+1\right]}{\omega}\right)$, its present value of (limited) depreciation allowances stays the same, namely $\int_{0}^{\frac{\log \left[\frac{A \cdot \omega}{C F}+1\right]}{\omega}} C F \cdot e^{t \cdot\left(\omega-i_{s}\right)} d t$ and $B(T)=0$.

Using the density function we can calculate the expected present value of tax savings:

$$
\mathrm{E}(\mathrm{PV})=\mathrm{s} \int_{0}^{\infty} P V(T) \cdot \lambda \cdot e^{-T \cdot \lambda} d T
$$

with the particular solution in the case of an irreversible investment assuming $K=0$ (for the derivation of the general solution see Appendix A3):

$$
\mathrm{E}(\mathrm{PV})_{K=0}=s \frac{\mathrm{CF}\left(1-\left(1+\frac{\mathrm{A} \omega}{\mathrm{CF}}\right)^{1-\frac{\lambda+i_{S}}{\omega}}\right)}{\lambda+i_{S}-\omega}
$$

The only difference compared to formula (7) is the use of $i_{s}+\lambda$ instead of $i_{s}$ as discount factor. For that reason, all findings concerning the optimal step-up

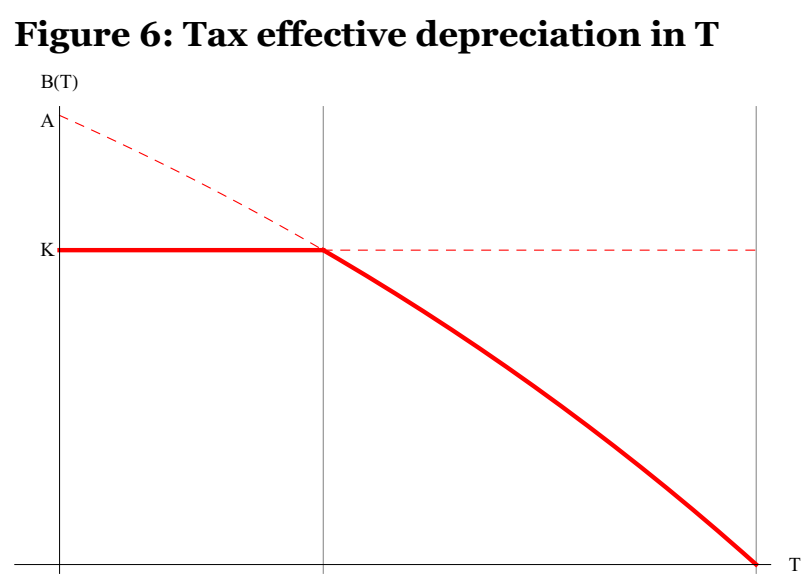


value or the maximum step-up value from section 2 are also valid here.

If $K \geq A$, i.e. no matter at what (early) point in time the cash flows stop, the step-up value $A$ always becomes fully tax effective and the expected tax savings can be determined as weighted average of the step-up value and formula (33).

$$
\begin{aligned}
& \mathrm{E}(\mathrm{PV})_{K \geq A}= \\
& s_{\frac{\lambda}{\lambda+i_{s}}} A+\left(1-\frac{\lambda}{\lambda+i_{s}}\right) E(P V)_{K=0}
\end{aligned}
$$

For $0<K<A$ the general solution of (32) is given in the appendix A3.

Figure 7 depicts the course of these functions depending on $\lambda$ for $\mathrm{CF}:=.03, s:=.4, s_{r}:=.2, i_{s}:=$ $.06, \omega:=.03, A:=1$.

The functions show opposite courses. Function (30) increases in $\lambda$. A rising $\lambda$ means that more investment projects die before their useful lives have ended. Thus, the average depreciation period shortens while the step-up value is fully tax effective; therefore the expected present value of depreciation allowances rises. Of course, this does not mean that the investment project becomes more advantageous, but only the NPV of the step-up. The situation is different if depreciation allowances are limited by the cash flows. Here, the course of the functions depends on the parameter $K$. If the investment is fully reversible $(K \geq A)$, the same effect can be observed, the NPV function rises and for $\lambda \rightarrow \infty$ both functions converge. In the case of a partly reversible investment the function shows a considerably lower slope and limit value. Finally, if the investment is irreversible ( $K=0)$, the function has a negative slope as there is no positive

Figure 7: NPV depending on $\lambda$ for $C F:=.03$, $s:=.4, s_{r}:=.2, i_{s}:=.06, \omega:=.03, A:=1$, $U L:=10$

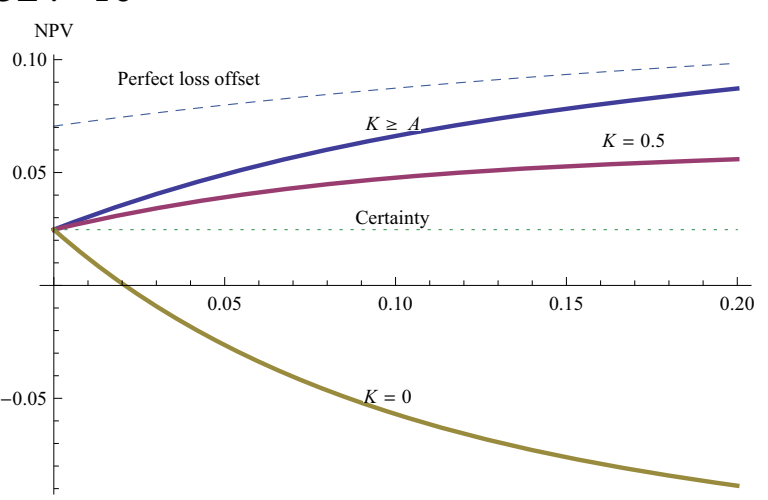

effect due to a higher $\lambda$, since the depreciation of the residual book value cannot become tax effective because there are no cash receipts to be offset against.

The effects on the step-up investment $(N P V)$ can be seen in Figure $8\left(\mathrm{CF}:=.03, s:=.4, s_{r}:=.2, i_{s}:=\right.$ $.06, \omega:=.03, \lambda:=0.02$ ).

Corresponding to the functions in figure 7 the maximum step-up value increases $(K=A, K=$ $0.5)$ or decreases $(K=0)$ compared to the certainty case.

\section{Optimal timing}

Finally I analyze whether a positive NPV should be realized in the current period or in later periods. I consider two scenarios.

\subsection{Step-up value increases with rate $\omega$}

If the step-up value-especially in the case of goodwill-is determined by discounting the future cash flows of the firm, it can be assumed that it increases at the same rate $\omega$ as the cash flows $\left(A(t)=A e^{t \cdot \omega}\right)$. The expected NPV of the step-up investment depending on time $t$ can, therefore, be expressed as follows using the discount factor from formula (33) $\left(\lambda+i_{s}\right)$

$$
\begin{aligned}
& \mathrm{E}(\mathrm{NPV}(\mathrm{t}))=\mathrm{e}^{-t \cdot\left(i_{s}+\lambda-\omega\right)} \cdot \\
& \left(\frac{\mathrm{CF} \cdot \cdot \cdot\left(-1+\left(1+\frac{A \omega}{\mathrm{CF}}\right)^{1-\frac{\lambda+i_{s}}{\omega}}\right)}{\omega-i_{s}-\lambda}-A \cdot s_{r}\right)
\end{aligned}
$$

There are two opposing effects. On the one hand, a positive NPV that is realized in later periods

Figure 8: $\boldsymbol{N P V}$ depending on $A$ for $C F$ := $.03, s:=.4, s_{r}:=.2, i_{s}:=.06, \omega:=.03, \lambda:=0.02$, $U L:=10$

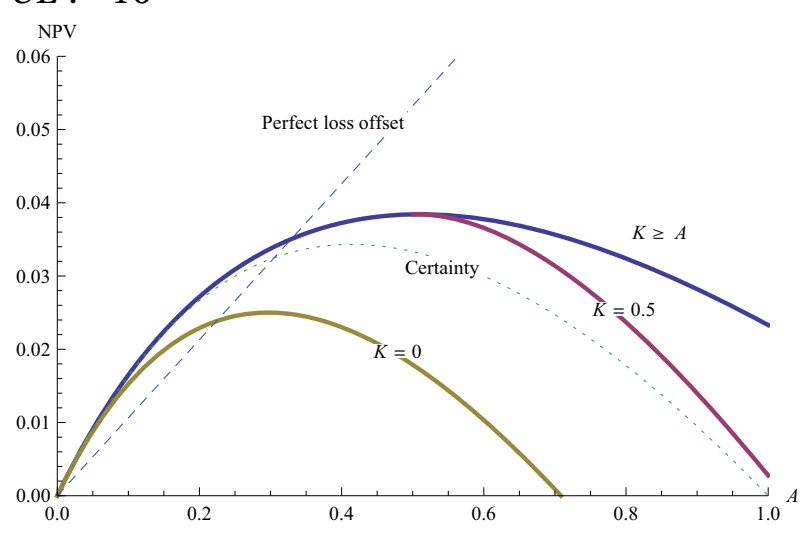


decreases in value as it has to be discounted, like cash flows that accrue in the future. On the other hand, the step-up value is higher. The derivative of (35) with respect to $t$ depends on the sign of the expression $-t\left(i_{s}+\lambda-\omega\right)$ and shows the predominant effect. There is no optimal point in time at which the NPV should be realized. These results are also valid for the perfect loss offset.

\subsection{Step-up value remains constant}

On the other hand, it is possible that the hidden reserves remain constant over time. This could be the case if, for example, buildings are revalued by means that do not reflect the firm's specific cash flows. In the case of a perfect loss offset there is no value of waiting since postponing the investment has no positive effect. If we assume an imperfect loss offset, even though the step-up value does not increase, it is amortized faster because of rising cash receipts. Now there is a point in time at which one effect outweighs the other. The calculus can be formulated as follows:

$$
\begin{aligned}
& \mathrm{E}(\mathrm{NPV}(\mathrm{t}))=\mathrm{e}^{-t \cdot\left(i_{s}+\lambda\right)} \cdot \\
& \left(\frac{\mathrm{CF}^{t \cdot \omega} s\left(-1+\left(1+\frac{A \omega}{\mathrm{CF} \cdot e^{t \cdot \omega}}\right)^{1-\frac{i_{s}+\lambda}{\omega}}\right)}{\omega-i_{s}-\lambda}-A \cdot s_{r}\right)
\end{aligned}
$$

A general analytical optimization is neither possible nor necessary. The advantage of postponing the step-up investment consists exclusively of the fact that the stepped-up book values are amortized faster when starting with a higher $\mathrm{CF}$ in $\mathrm{t}=\mathrm{o}$. There is no advantage if cash flows do not rise over time $(\omega \leq 0)$; even if they do, the effect is quite small. It is hence reasonable to analyze the case of maximum growth rates. When assuming an infinite cash flow series the growth rate must be less than or equal to $i_{s}+\lambda$ to achieve reasonable valuation results; formula (36) is not defined for $\omega \rightarrow i_{s}+\lambda$. Using l'Hôpital's rule, formula (36) simplifies to:

$$
\begin{aligned}
& \lim _{\omega \rightarrow i_{s}+\lambda} E(N P V(t))= \\
& \frac{\mathrm{CF} \cdot s \cdot \log \left(1+\frac{A \cdot e^{-t\left(\lambda+i_{s}\right)}\left(\lambda+i_{s}\right)}{\mathrm{CF}}\right)}{\lambda+i_{s}}-A \cdot e^{-t\left(\lambda+i_{s}\right)} \cdot s_{r}
\end{aligned}
$$

Differentiating (37) with respect to $t$ and equating zero yields:

$$
\begin{aligned}
& \text { (38)A } \cdot\left(\lambda+i_{s}\right)\left(e^{-t^{*}\left(\lambda+i_{s}\right)} s_{r}-\frac{s}{e^{t^{*}\left(\lambda+i_{s}\right)}+\frac{A}{C F}\left(\lambda+i_{s}\right)}\right) \\
& =\mathrm{O}
\end{aligned}
$$

By solving (38) for $t^{*}$ the optimal point of time for a step-up is derived:

$$
\mathrm{t}^{*}=\frac{\log \left(\frac{A\left(\lambda+i_{s}\right) s_{r}}{\mathrm{CF}\left(s-s_{r}\right)}\right)}{\lambda+i_{s}}
$$

Figure (9) illustrates the course of the optimal stepup time depending on $A$ for $\mathrm{CF}:=.08, s:=.5, s_{r}:=$ $.2, i_{s}:=.06, \lambda:=.07$; the maximum step-up value for these parameters is $A^{\operatorname{Max}}:=2.5$.

$t^{*}$ increases with a rising step-up value $A$; this is because the higher the step-up value $A$ in relation to the starting cash flow $C F$, the greater the effect of waiting. A relatively low starting cash flow $C F$ means that the tax-effective cash flow period will stretch over a long period of time. In this case, shifting future tax-effective efforts to earlier periods (by means of waiting) increases the net present value more than if the depreciation period is already quite short because of high current cash flows. Negative values of $t^{*}$ indicate that the optimum point in time lies in the past.

\section{Conclusion and Outlook}

The assumption of a perfect loss offset may be reasonable when analyzing small investment projects. Depreciation allowances that exceed the cash flows of the current period can be offset against profits of other investment projects, which lower the tax payments of the firm. In the case an entire firm is revalued this argument is not valid and decisions

Figure 9: Optimal timing for $C F:=.08$,

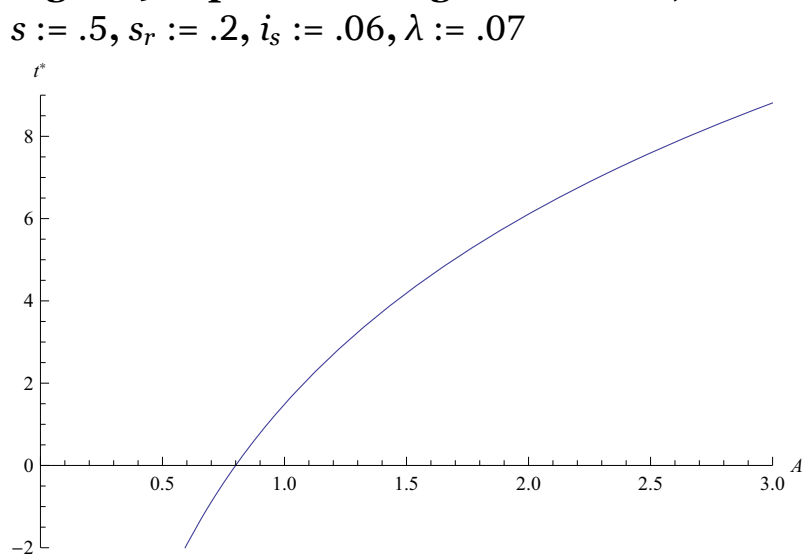


cannot be made just by looking at the depreciation allowances. When assuming an imperfect loss-offset the step-up decision changes in many ways. First, even in the case of an advantageous depreciation method the NPV of the step-up investment features both a maximum and a zero point, i.e., there is a step-up value that is optimal and should be realized if possible, and a step-up value above which the step-up investment becomes disadvantageous. Second, the acquisition premium in the case of an asset deal may be considerably smaller.

I have been able to show that a simplified approach that focuses only on the cash flows is in most cases able to determine the maximum step-up value. The detailed approach is quite complex, even in the simple deterministic case.

Using this simplified approach I have been able to implement an uncertain lifetime of the investment which can cause the maximum step-up value to rise or to fall depending on the degree of irreversibility of the underlying investment.

Furthermore, I have been able to show that it can be reasonable under certain conditions not to realize positive NPVs of step-up investments immediately, but in future periods. Generally this is only reasonable for relatively high growth rates. An optimal trigger point has been determined for step-up values that remain constant over time.

Future research should lay special emphasis on extending the model. In the present paper uncertainty is only expressed in the lifetime of the investment project, but not in the cash flows themselves. The implementation of stochastic cash flows may provide additional insights.

\section{Appendix}

\section{A1: Lambert W-Function}

The Lambert $\mathrm{W}$ function (W) is defined as the inverse function of $f(w)=w \cdot e^{w}$ and thus verifies $z=W(z) \cdot e^{W(z)}$. To solve economic equations only the real-valued part of the Lambert $\mathrm{W}$ function is relevant; in this case $\mathrm{W}$ is only defined for $w>\frac{-1}{e}$. The function $W(z)$ is multivalued for $\frac{-1}{e} \leq z<0$, i.e. there are two possible real values of $W(z)$. The solution of the second branch satisfying $W(z) \leq-1$ is normally referred to as $W_{-1}(z)$, (s. ChapeauBlondeau and Monir 2002).

Figure 10 depicts the course of the Lambert W function.
There are numerous applications of the Lambert W function, e.g., combinatorial problems or iterated exponentiation, but with regard to the present paper the function is used to solve equations, which would have no closed form solution otherwise (Corless, Gonnet, Hare, Jeffrey, and Knuth 1996). In the following I show how equation (14) is derived from equation (11); all other expressions using the Lambert $\mathrm{W}$ function can be derived analogously.

$$
\text { (40) } \begin{aligned}
& \frac{\mathrm{CF} \cdot\left(1-e^{-\frac{A \cdot i_{s}}{\mathrm{CF}}}\right) s}{i_{s}}-A \cdot s_{r}=0 \Rightarrow \\
& \frac{\mathrm{CF}}{i_{s}}\left(1-\frac{1}{e^{\frac{A \cdot i_{s}}{\mathrm{CF}}}}\right)=A \cdot \frac{s_{r}}{s} \Rightarrow \\
& -\frac{\mathrm{CF}}{i_{s}}=A \cdot e^{\frac{A \cdot i_{s}}{\mathrm{CF}}} \cdot \frac{s_{r}}{s}-e^{\frac{A \cdot i_{s}}{\mathrm{CF}}} \cdot \frac{\mathrm{CF}}{i_{s}} \Rightarrow \\
& -\frac{\mathrm{CF}}{i_{s}}=e^{\frac{A \cdot i_{s}}{\mathrm{CF}}} \cdot\left(A \cdot \frac{s_{r}}{s}-\frac{\mathrm{CF}}{i_{s}}\right) \Rightarrow \\
& -\frac{\mathrm{CF}}{i_{s}} \cdot e^{-\frac{s}{s_{r}}}=e^{\frac{A \cdot i_{s}}{\mathrm{CF}}-\frac{s}{s_{r}}} \cdot\left(A \cdot \frac{s_{r}}{s}-\frac{\mathrm{CF}}{i_{s}}\right) \Rightarrow \\
& -\frac{s}{s_{r}} \cdot e^{-\frac{s}{s_{r}}}=e^{\frac{A \cdot i_{s}}{\mathrm{CF}}-\frac{s}{s_{r}}} \cdot\left(A \cdot \frac{i_{s}}{\mathrm{CF}}-\frac{s}{s_{r}}\right) \Rightarrow \\
& W\left(-\frac{s}{s_{r}} \cdot e^{-\frac{s}{s_{r}}}\right)=A \cdot \frac{i_{s}}{\mathrm{CF}}-\frac{s}{s_{r}} \Rightarrow \\
& A=\frac{C F \cdot\left(W\left(-\frac{s}{s_{r}} \cdot e^{-\frac{s}{s_{r}}}\right)+\frac{s}{s_{r}}\right)}{i_{s}}
\end{aligned}
$$

\section{A2: Derivation of equation (16)}

Setting equation (12) equal to zero yields:

\section{Figure 10: The Lambert W-Function}

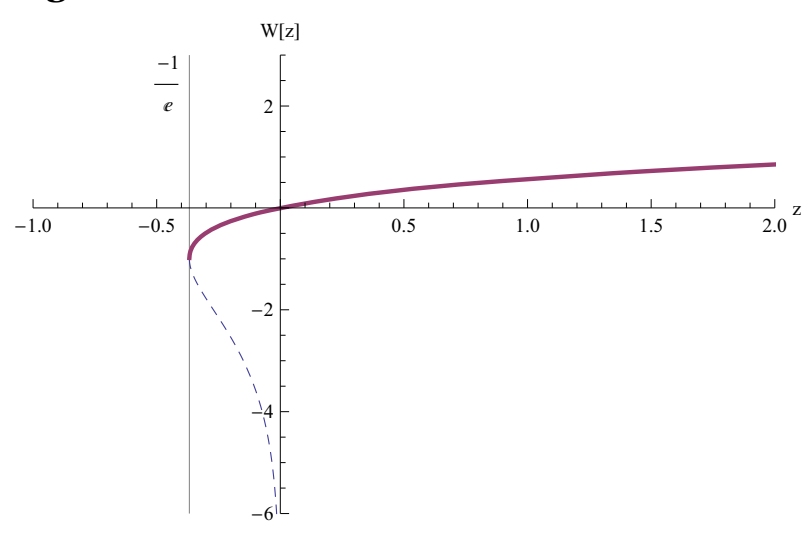




$$
\begin{aligned}
\text { (41) } & -\mathrm{A}^{\operatorname{Max}} \cdot s\left(\frac{A^{\text {Max }} \dot{i}_{s}}{2 \mathrm{CF}}-1\right)-A^{\operatorname{Max}} \cdot s_{r}=0 \\
& \rightarrow A^{\operatorname{Max}}=\frac{2\left(\mathrm{CFs}-\mathrm{CFs}_{r}\right)}{s \cdot i_{s}}
\end{aligned}
$$

As the decreasing cash flow series approaches zero in the long run, unlike with a rising or constant cash flow series there are only limited tax-effective cash flows to be offset against depreciation allowances, namely $\int_{0}^{\infty} \mathrm{CF} \cdot e^{-i_{s} \cdot t} d t=\frac{\mathrm{CF}}{i_{\mathrm{s}}}$ for $\omega=-i_{s}$. The relationship between reduced tax rate and regular tax rate determines whether the maximum step-up value lies below or above this threshold:

$$
\frac{2\left(\mathrm{CFs}-\mathrm{CFs}_{r}\right)}{s \cdot i_{s}} \leq \frac{\mathrm{CF}}{i_{s}} \rightarrow s_{r} \geq \frac{s}{2}
$$

From this point onwards $\left(s_{r}<\frac{s}{2}\right)$, despite a rising step-up value, the sum of tax-effective cash flows remains constant $\left(\frac{\mathrm{CF}}{i_{\mathrm{s}}}\right)$. The maximum stepup value in this case can be determined by setting $A:=\frac{\mathrm{CF}}{i_{s}}$ in the first part of (12) and solving for $A^{\text {Max: }}$

$$
\begin{aligned}
& -\frac{\mathrm{CF}}{i_{s}} S\left(\frac{\frac{\mathrm{CF}}{i_{s}} i_{s}}{2 \mathrm{CF}}-1\right)-A^{\operatorname{Max}} \cdot s_{r}=0 \rightarrow \\
& A^{\operatorname{Max}}=\frac{\mathrm{CF} \cdot s}{2 i_{s} \cdot s_{r}}
\end{aligned}
$$

\section{A3: General solution to equation (32)}

Part of $A$ which has not yet been tax-effective depending on $\mathrm{T}$ :

$$
\text { (44) } \mathrm{B}(\mathrm{T})=\mathrm{A}-\int_{0}^{T} \mathrm{CF} e^{t \omega} d t=A-\frac{\mathrm{CF}\left(e^{T \omega}-1\right)}{\omega}
$$

Point in time at which $B(T)$ falls below $K$ :

$$
\begin{aligned}
& \mathrm{B}\left(\mathrm{T}^{*}\right)=A-\frac{\mathrm{CF}\left(e^{T^{*} \omega}-1\right)}{\omega}=K \Rightarrow \\
& \mathrm{T}^{*}=\frac{\log \left[\frac{\left(A-K+\frac{C F}{\omega}\right) \omega}{C F}\right]}{\omega}
\end{aligned}
$$

The second threshold $(B(T)=0)$ is given by formula (6). Therefore, the expected present value of the tax savings reads:

$$
\text { (46) } \mathrm{E}(\mathrm{PV})=
$$

$$
\begin{gathered}
\mathrm{s} \int_{0}^{T^{*}}\left(P V(T)+K \cdot e^{-T \cdot i_{s}}\right) \cdot \lambda \cdot e^{-T \cdot \lambda} d T+ \\
\mathrm{s} \int_{T^{*}}^{x}\left(P V(T)+B(T) \cdot e^{-t \cdot i_{s}}\right) \cdot \lambda \cdot e^{-T \cdot \lambda} d T+ \\
\quad \mathrm{s} \int_{x}^{\infty} P V(x) \cdot \lambda \cdot e^{-T \cdot \lambda} d T
\end{gathered}
$$

After a few conversion steps one yields:

$$
\begin{aligned}
& \mathrm{E}(\mathrm{PV})= \\
& s \frac{\lambda}{\lambda+i_{S}}\left(\frac{\mathrm{CF}\left(1-\left(1+\frac{(A-K) \omega}{\mathrm{CF}}\right)^{1-\frac{\lambda+i_{S}}{\omega}}\right)}{\lambda-\omega+i_{S}}+K\right) \\
& +\mathrm{S}\left(1-\frac{\lambda}{\lambda+i_{S}}\right) \frac{\mathrm{CF}\left(1-\left(1+\frac{A \omega}{\mathrm{CF}}\right)^{1-\frac{\lambda+i_{S}}{\omega}}\right)}{\lambda-\omega+i_{S}}
\end{aligned}
$$

\section{Acknowledgements}

I would like to thank two anonymous referees and the department editor, Rainer Niemann, for their very valuable suggestions, which helped to improve the paper considerably.

\section{References}

Brähler, Gernot, Max Göttsche, and Bernhard Rauch (2009): Verlustnutzung von Kapitalgesellschaften bei Umwandlungen - Eine ökonomische Vorteilhaftigkeitsanalyse, Zeitschrift für Betriebswirtschaft, 79 (10): 1175-1191.

Chapeau-Blondeau, François and Abdelilah Monir (2002): Numerical Evaluation of the Lambert W Function and Application to Generation of Generalized Gaussian Noise With Exponent 1/2, IEEE Transactions on Signal Processing, 50 (9): 2160-2165.

Corless, Robert M., Gaston H. Gonnet, D. E. G. Hare, David J. Jeffrey, and Donald E. Knuth (1996): On the Lambert W Function, Advances in Computational Mathematics, 5 (1): 329-359.

DeAngelo, Harry and Ronald W. Masulis (1980): Optimal Capital Structure Under Corporate and Personal Taxation, Jounal of Financial Economics, 8 (1): 3-29.

Diller, Markus (2008): Effektive Seuerbelastungen bei unvollständigem Verlustausgleich und unsicheren Erwartungen, Die Betriebswirtschaft, 68 (4): 404-417.

Dixit, Avinash K. and Robert S. Pindyck (1994), Investment Under Uncertainty, Princeton Univ. Press: Princeton.

Erickson, Merle (1998): The Effect of Taxes on the Structure of Corporate Acquisitions, Journal of Accounting Research, 36 (2): 279-298.

Erickson, Merle and Shiing-Wu Wang (2000): The Effect of Transaction Structure on Price: Evidence from Subsidiary Sales, Journal of Accounting and Economics, 30 (1): 59-97.

Erickson, Merle and Shiing-Wu Wang (2007): Tax Benefits as a Source of Merger Premiums In Acquisitions of Private Corporations, Accounting Review, 82 (2): 359-387.

Gryglewicz, Sebastian, Kuno J. M. Huisman, and Peter M. Kort (2008): Finite Project Life and Uncertainty Effects on Investment, Journal of Economic Dynamics and Control, 32 (7): 2191-2213.

MacKie-Mason, Jeffrey K.(1990): Do Taxes Affect Corporate Financing Decisions?, Journal of Finance, 45 (5): 1471-1493.

McDonald, Robert L. and Daniel R. Siegel (1986): The Value of Waiting to Invest, Quarterly Journal of Economics, 101 (4): 707-727.

Müller, Heiko and Birk Semmler (2003a): Das Entscheidungsproblem der Wahl des steuerlichen Wertansatzes bei einer Einbringung in eine Kapitalgesellschaft nach $\S 20$ UmwStG, Steuer \& Studium, 24 (4): 203213

Müller, Heiko and Birk Semmler (2003b): Steuerbedingter Kaufpreisabschlag bei Anteilen an einer Kapitalgesellschaft, Zeitschrift für Betriebswirtschaft, 73 (6): 583-599. 
Müller, Heiko, Dirk Langkau, and Thomas-Patrick Schmidt (2011): Etragsteueroptimale Alternativen zur Umwandlung einer Kapitalgesellschaft in ein Personenunternehmen, Zeitschrift für betriebswirtschaftliche Forschung, 63 (2): 90-117.

PwC (2006): Mergers and Acquisitions: A Global Tax Guide with a Country-by-Country Guide, Wiley \& Sons: New Jersey.

Schipper, Katherine and Abbie Smith (1991): Effects of Management Buyouts on Corporate Interest and Depreciation Tax Deductions, Journal of Law and Economics, 34 (2): 295-341.

Scholes, Myron S., Mark A. Wolfson, Merle Erickson, Edward L. Maydew, and Terry Shevlin (2009): Taxes and Business Strategy - A Planning Approach, 4th ed., Pearson: New Jersey.

Schreiber, Ulrich (2008): Besteuerung der Unternehmen, 2th ed., Springer: Berlin, Heidelberg.
Trezevant, Robert (1992): Debt Financing and Tax Status: Tests of the Substitution Effect and the Tax Exhaustion Hypothesis Using Firms' Responses to the Economic Recovery Tax Act of 1981, Journal of Finance, 47 (4): $1557-1568$.

\section{Biography}

Markus Diller has held the Chair of Business Taxation at the University of Paderborn from 2008 to 2010 and the Chair of Business Taxation at the University of Passau since 2010. Diller received his Ph.D. (in 2003) and his Habilitation (in 2008) from the University of Passau. His main fields of research are the impact of taxation on entrepreneurial decisions and tax-planning. 